\title{
An experimental analysis of the end-notched flexure composite laminates beams with elastic couplings
}

Received: 10 March 2020 / Accepted: 8 July 2020 / Published online: 31 July 2020

(C) The Author(s) 2020

\begin{abstract}
This paper presents an experimental study of the composite beams with elastic couplings subjected to the end-notched flexure (ENF) test. The object of research were carbon/epoxy composite laminates with specific stacking sequences exhibiting the bending-extension and the bending-twisting couplings. In addition, multidirectional laminates with different delamination interfaces were tested. Influence of elastic coupling phenomena on behavior of laminates subjected to the bending moment as well as on fracture toughness and delamination surfaces after the ENF tests was discussed. All experiments were performed according to the ASTM D7905 Standard. Determination of crack initiation was supported by the acoustic emission technique. Data analysis of the ENF test was performed by using both the direct beam theory and the corrected beam theory. Results obtained by using the classical data reduction schemes were compared with the compliancebased beam method (CBBM). Greater values of the fracture toughness obtained by using the non-standardized methods can be explained by the effect of the fracture process zone which was taken into account in the CBBM calculation scheme. Delamination surfaces of coupled laminates after the ENF tests were investigated by using the scanning electron microscopy. Results revealed that the effect of elastic couplings might influenced on intense bridging phenomena, more extensive fracture process zone and contribution of the mode III in total delamination resistance. Nevertheless, application of the standardized ENF procedure to determination of the fracture toughness of laminates exhibiting elastic couplings is still possible, provided assistance of additional data reduction schemes and techniques or numerical analysis.
\end{abstract}

Keywords Elastic couplings · Composite laminates · ENF test $\cdot$ Acoustic emission $\cdot$ SEM

\section{Introduction}

Fiber-reinforced plastic (FRP) laminates, besides steel, are widely used in many industry sectors. The main advantages of polymeric composites are high strength and corrosion resistance. The most common type of failure in FRP laminates is delamination which is the major weakness of advanced composite structures. Another problem which can have a considerable effect on delamination resistance may be an elastic coupling phenomena which may be present when laminates are manufactured with specific configuration of layers. The fracture toughness $\left(G_{\mathrm{C}}\right)$ in the form of the critical strain energy release rate (c-SERR) values can be determined for three basic modes including the mode I (tensile opening), the mode II (in-plane shear) and the mode III (transverse shear). Among them, the mode II delamination is one of the common damages in the industrial structures because of applying flexural loads to the parts. There are various standardized test methodologies available to determine the mode II fracture toughness of fiber-reinforced polymer composites,

Communicated by Johlitz, Laiarinandrasana and Marco.

J. Rzeczkowski $(\square)$

Faculty of Fundamentals of Technology, Lublin University of Technology, Nadbystrzycka 38, 20-618 Lublin, Poland

E-mail: j.rzeczkowski@pollub.pl 
namely the end-notched flexure (ENF) test [1], the end-loaded split (ELS) [2] test and the mix-mode bending (MMB) test [3]. All these methods are widely used by the scientific community and the industry to obtain the fracture properties of materials. The advantages and limitations of each configuration were reviewed in [4] where it was found that one of the main problems in the mode II testing is poor comparability among the existing test methods. The causes of such discrepancies in results are diverse, ranging from the friction $[5,6]$ and large deflections involved, to the complex damage mechanism occurring at the crack tip. Nevertheless, the end-notched flexure is among others the most widely used technique to study the mode II fracture owing to only requiring a common three-point bending fixture. Therefore, many researchers have examined the mode II delamination of laminated composites by using the ENF test [7-16].

The respective ASTM Standards cover the measurements of the $G_{\text {IIC }}$ only of unidirectional (UD) laminates. However, most applications in composite structures involve multidirectional (MD) laminates, in which delamination tends to occur between layers of different orientations. Moreover, MD laminates usually present elastic couplings which can be the source of significant errors in the $G_{\text {IIC }}$ measurements [17]. Couplings lead to a non-uniform distribution of the energy release rate along delamination front [18] resulting in skewed and curved crack fronts when propagating an initially straight crack in fracture test and possibly also mix-mode effects. This may in turn lead to an error in the evaluation of the fracture toughness based on analysis which assumes a uniform crack extension across the specimen width and assumption of fracture mode from global considerations. Davidson et al. [19] presented a three-dimensional finite element results for the energy release rate (ERR) distribution in symmetric and antisymmetric ENF specimens. It has been shown that the difference between the maximum and minimum ERRs along the delamination front is a function of the specimen's $D_{c}$ ratio. It has also been shown that the asymmetry in the energy release rate distribution about the center of the specimen's width is a function of the $B_{t}$ ratio. For the ENF loading, the peak energy release rates occurred at one or both edges of specimen. Moreover, larger bending-twisting coupling resulted in larger asymmetries in the energy release rate, whereas larger longitudinal-transverse bending coupling resulted in larger peak values. Similar conclusions were drawn by Samborski [20]. He performed a numerical study concerned the mode II critical strain energy release rate distribution along delamination front in mechanically coupled laminated composites subjected to the standardized end-notched flexure test described in the ASTM D7905 Standard. Finite element results indicated that the assumptions of the uniform distribution of the mode II SERR along delamination front typical for unidirectional laminates were no longer valid for the general ply-angle laminates. The strongest deviations of the $G_{\mathrm{II}}$ distributions were observed for the laminated beam models exhibiting simultaneous bending-extension/extension-twisting/shearing-bending coupling. Apart from numerical simulations, many researchers conducted experimental determination of the mode II interlaminar fracture of multidirectional composite laminates. Ozdil et al. [21] prepared the ENF tests on unidirectional and angle-ply E-glass/polyester specimens and revealed that the fracture toughness increased with increased angle $\theta$ at the $\pm \theta$ interface. This is attributed to the fracture work associated with debonding of transversely oriented fiber bundles in the quasi-unidirectional plies. Moreover, post-fracture examination of the specimens revealed deviations of the crack front form its initial straight shape in all specimens as a result of elastic coupling effects in the laminate beams. Pereira et al. [22] prepared experimental study on the mode II fracture toughness of carbon/epoxy multidirectional laminates with delamination interfaces $0^{\circ} / / 0^{\circ}, \theta / / \theta$ and $0^{\circ} / / \theta$. Experimental

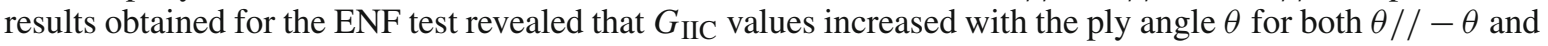
$0 / / \theta$ specimens. Similar conclusions were drawn in [23] where glass/epoxy multidirectional laminates were subjected to the end-notched flexure test.

Although the ENF test is a widely used technique to study the mode II fracture, it suffers from a limited number of reliable and precise data about crack propagation and process zone phenomena. Actually, the difficulties in monitoring crack propagation and the fiber bridging phenomena often limit the mode II test to the measurement of initiation toughness values. Moreover, the lack of crack opening and the particularly large fracture process zone (FPZ) associated with the mode II delamination pose additional problem in defining the crack tip position during the test. Therefore, a so-called the compliance-based beam method (CBBM) $[24,25]$ has been proposed to overcome those difficulties and to take into account the effect of the FPZ on the

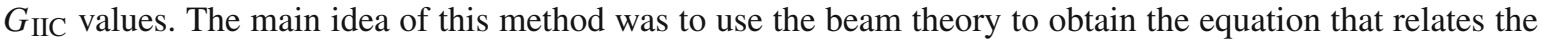
current compliance and the crack length. This equation can be used to estimate the equivalent crack length as a function of current compliance. The standardized test methods based on visual crack length monitoring show differences in determination of the fracture toughness because they mainly depend on the measurements of the crack length and a well-defined crack tip does not exist when testing laminates under the mode II loadings. Therefore, they are not reliable for measuring the fracture toughness. On the contrary, methods that are not based on a direct measurement of the crack length such as the CBBM, results in small differences between the 
different test typologies and materials. Even though the CBBM is based on linear elastic fracture mechanics (LEFM) it rely on calculating an equivalent crack length that somehow takes into account the FPZ length. This is why the CBBM results show better agreement with an experiment.

In practice, determination of the interlaminar fracture resistance may be a challenge when elastic couplings occurred in laminate. Therefore, in this situation the question of author of this paper is, whether the standardized test methods of determination of the mode II fracture toughness-elaborated for the unidirectional (UD) composites with the respective data reduction schemes are still valid.

In the present work an experimental determination of the mode II fracture toughness of carbon/epoxy composite laminates with elastic couplings was prepared. Critical strain energy release rates were obtained both for the classical data reduction schemes and for the method based on equivalent crack concept (compliancebased beam method). Recognition of delamination initiation was supported by the acoustic emission technique. Delamination surface of coupled laminates after the ENF tests were investigated by using SEM analysis. Novelty in the present article is an experimental evaluation of the influence of elastic couplings phenomena on delamination process and fracture toughness of the carbon/epoxy composite laminates subjected to the mode II end-notched standardized test.

\section{Elastic coupling phenomena}

The response of laminate beams subjected to the ENF test may be examined by using the laminate constitutive equations according to the classical laminate theory (CLT)

$$
\left\{\begin{array}{l}
\mathbf{N} \\
\mathbf{M}
\end{array}\right\}=\left[\begin{array}{ll}
\mathbf{A} & \mathbf{B} \\
\mathbf{B} & \mathbf{D}
\end{array}\right]\left\{\begin{array}{l}
\varepsilon^{0} \\
\boldsymbol{\kappa}^{0}
\end{array}\right\}
$$

where $\mathbf{N}$ and $\mathbf{M}$ are the force and moment resultants, $\varepsilon^{0}$ and $\varkappa^{0}$ are the mid-plane strains and curvatures and $\mathbf{A}, \mathbf{B}$ and $\mathbf{D}$ are the extensional, the coupling and the bending stiffness matrices, respectively, and are defined as follows:

$$
\begin{aligned}
A_{i j} & =\sum_{k=1}^{n}\left[\bar{Q}_{i j}\right]_{k}\left(z_{k}-z_{k-1}\right)=\sum_{k=1}^{n}\left[\bar{Q}_{i j}\right]_{k} t_{k} \\
B_{i j} & =\frac{1}{2} \sum_{k=1}^{n}\left[\bar{Q}_{i j}\right]_{k}\left(z_{k}^{2}-z_{k-1}^{2}\right)=\sum_{k=1}^{n}\left[\bar{Q}_{i j}\right]_{k} t_{k} z_{k}^{c} \\
D_{i j} & =\frac{1}{3} \sum_{k=1}^{n}\left[\bar{Q}_{i j}\right]_{k}\left(z_{k}^{3}-z_{k-1}^{3}\right)=\sum_{k=1}^{n}\left[\bar{Q}_{i j}\right]_{k}\left(t_{k}\left(z_{k}^{c}\right)^{2}+\frac{t_{k}^{3}}{12}\right) .
\end{aligned}
$$

Here, $i, j=1 \ldots 6, z_{k}$ is the distance from laminate mid-plane to the top of the kth ply, $z_{k}^{c}$ is the $k$ th ply center of gravity location parameter counting from the neutral plane, $t_{k}$ is the $k$ th ply thickness and $\bar{Q}_{i j}$ stands for the transformed reduced stiffness matrix.

Laminate behavior under the mode II loading is dependent on the components of each of the coupling $\mathbf{B}$ and the bending $\mathbf{D}$ stiffness matrices. Namely, for the bending-twisting (BT) coupled laminate with $[\theta / 0 / \theta / \theta / 0 /-$ $\theta / 0 /-\theta /-\theta /-\theta /-\theta / 0 /-\theta / \theta / 0 / 0 / \theta / \theta]$ ply sequence the forms of each of the $\mathbf{B}$ and the $\mathbf{D}$ matrices are as follows:

$$
[\mathbf{B}]=\left[\begin{array}{lll}
0 & 0 & 0 \\
0 & 0 & 0 \\
0 & 0 & 0
\end{array}\right], \quad[\mathbf{D}]=\left[\begin{array}{ccc}
D_{11} & D_{12} & D_{16} \\
D_{21} & D_{22} & D_{26} \\
D_{16} & D_{26} & D_{66}
\end{array}\right]
$$

whereas, for the bending-extension (BE) laminate with $[\theta /-\theta / 0 /-\theta / 0 / \theta / 90 / \theta /-\theta]$ stacking sequence, the coupling and the bending stiffness matrices were taken from:

$$
[\mathbf{B}]=\left[\begin{array}{ccc}
-B_{11} & 0 & 0 \\
0 & B_{22} & 0 \\
0 & 0 & 0
\end{array}\right], \quad[\mathbf{D}]=\left[\begin{array}{ccc}
D_{11} & D_{12} & 0 \\
D_{21} & D_{22} & 0 \\
0 & 0 & D_{66}
\end{array}\right]
$$

Application of bending moment $M_{x}$ to the BT laminate produced twisting curvature around its central axis which was caused by nonzero $D_{16}$ term. In addition, the coupling matrix $\mathbf{B}$ was uncoupled which meant absence 
Table 1 Mechanical properties of carbon/epoxy

\begin{tabular}{llll}
\hline$E_{1}(\mathrm{GPa})$ & $E_{2}(\mathrm{GPa})$ & $v_{12}(-)$ & $G_{12}=G_{13}(\mathrm{GPa})$ \\
\hline 112.105 & 7.421 & 0.27 & 3.338 \\
\hline
\end{tabular}

Table 2 Values of the non-dimenssional parameters $D_{c}$ and $B_{t}$ calculated for laminates with different delamination interfaces and elastic couplings

\begin{tabular}{lll}
\hline Interface & $D_{c}$ & $B_{t}$ \\
\hline $30^{\circ} / / 30^{\circ}$ & 0.0048 & $6.12 \times 10^{-5}$ \\
$45^{\circ} / / 45^{\circ}$ & 0.0048 & $4.75 \times 10^{-5}$ \\
$60^{\circ} / / 60^{\circ}$ & 0.0048 & $2.10 \times 10^{-5}$ \\
$30^{\circ} / /-30^{\circ}$ & 0.0048 & 0 \\
$45^{\circ} / /-45^{\circ}$ & 0.0048 & 0 \\
$60^{\circ} / /-60^{\circ}$ & 0.0048 & 0 \\
$\mathrm{BT}$ & 0.2384 & 0.2363 \\
$\mathrm{BE}$ & 0.4089 & 0 \\
\hline
\end{tabular}

of couplings between the bending moment and the mid-plane normal strains as well as between the twisting moment and the mid-plane shear strains. Considering the BE laminate, a $D_{16}$ component of the bending stiffness matrix was equal zero which caused absence of twisting curvatures. Moreover, the sub-laminates might experienced a mid-plane strain deformation in opposite directions caused by opposite signs of the $B_{11}$ term for the laminate arms above and below the mid-plane.

To examine possibility of non-uniform crack extension the non-dimensional parameters $D_{c}$ and $B_{t}$ (Eqs. 7, 8) [19] were calculated for the laminates with elastic couplings (BT and BE laminates) as well as for the laminates with $\left[0_{18}^{\circ} / \theta / / \theta / 0_{18}^{\circ}\right]$ and $\left[0_{16}^{\circ} / \theta / /-\theta / 0_{16}^{\circ}\right]$ stacking sequences in which delamination interfaces were respectively: $\theta / / \theta$ and $\theta / /-\theta$ where $\theta$ set angle was $\left\{30^{\circ}, 45^{\circ}, 60^{\circ}\right\}$. All calculations were based on the measured quasi-unidirectional ply properties (Table 1) of carbon/epoxy composite and were done by using MATLAB software environment. Obtained results of calculations were summarized in Table 2. Values of the $D_{c}$ parameter were constant for the specimens with interfaces $\theta / / \theta$ and $\theta / /-\theta$ and were equal 0.0048 . For the bending-twisting laminate value of this parameter reached 0.2384 . Nevertheless, for all these layups, however, $D_{c}$ was below the upper limit of 0.25 as suggested by Davidson et. al in [26]. The bending-extension laminate exhibited the greatest value of $D_{c}$ equal 0.4089 indicating tendency for non-uniform crack extension. The skewness parameter $B_{t}$ reached the greatest value for the BT specimen $\left(B_{t}=0.2363\right)$, which indicating in this case, that crack might propagated in a skewed manner. Although, for the multidirectional laminates with $\theta / / \theta$ interface the non-dimensional parameter $B_{t}$ was non-zero, its influence on delamination process was insignificant. For the remaining layups the $B_{t}$ values were equal zero.

$$
\begin{aligned}
D_{c} & =\frac{D_{12}^{2}}{D_{11} D_{22}} \\
B_{t} & =\frac{D_{16}}{D_{11}} .
\end{aligned}
$$

\section{Experimental work}

\subsection{Selection of the ENF specimens}

In order to study the influence of elastic couplings on the mode II fracture toughness two different types of specimens were subjected to the ENF test, namely elastic coupled laminates and multidirectional laminates. In practical point of view, specimens with specific stacking sequences which induce the elastic coupling phenomena are suspected to have the strongest negative effect on the conformity of the $G_{\text {IIC }}$ determination experiment with the standardized procedure. Therefore, the ENF tests were performed on the bending-twisting (BT) and the bending-extension (BE) coupled laminates exhibiting significantly high values of the parameters $D_{c}$ and $B_{t}$. In order to compare obtained results, considering the practical relevance and the results available in 
Table 3 Stacking sequences and interfaces of the ENF specimens

\begin{tabular}{lcc}
\hline Multidirectional laminates (note: ' $/ /$ ' & denotes position of initial delamination) & Interface \\
\hline Specimen no. & Stacking sequences & $30^{\circ} / / 30^{\circ}$ \\
\hline ENF-1 & $0_{16}^{\circ} / 30^{\circ} / / 30^{\circ} / 0_{16}^{\circ}$ & $45^{\circ} / / 45^{\circ}$ \\
ENF-2 & $0_{16}^{\circ} / 45^{\circ} / / 45^{\circ} / 0_{16}^{\circ}$ & $60^{\circ} / / 60^{\circ}$ \\
ENF-3 & $0_{16}^{\circ} / 60^{\circ} / / 60^{\circ} / 0_{16}^{\circ}$ & $30^{\circ} / /-30^{\circ}$ \\
ENF-4 & $0_{16}^{\circ} / 30^{\circ} / /-30^{\circ} / 0_{16}^{\circ}$ & $45^{\circ} / /-45^{\circ}$ \\
ENF-5 & $0_{16}^{\circ} / 45^{\circ} / /-45^{\circ} / 0_{16}^{\circ}$ & $60^{\circ} / /-60^{\circ}$ \\
ENF-6 & $0_{16}^{\circ} / 60^{\circ} / /-60^{\circ} / 0_{16}^{\circ}$ & \\
\hline Elastic coupled laminates & & \\
\hline Specimen no. & Stacking sequences (for one sub-laminate) & \\
\hline BT & {$\left[45^{\circ} / 0^{\circ} / 45^{\circ} / 45^{\circ} / 0^{\circ} /-45^{\circ} / 0^{\circ} /-45^{\circ} /-45^{\circ} /-\right.$} & $\left.45^{\circ} /-45^{\circ} / 0^{\circ} /-45^{\circ} / 45^{\circ} / 0^{\circ} / 0^{\circ} / 45^{\circ} / 45^{\circ}\right]$ \\
BE & {$\left[45^{\circ} /-45^{\circ} / 0^{\circ} /-45^{\circ} / 0^{\circ} / 45^{\circ} / 90^{\circ} / 45^{\circ} /-45^{\circ}\right]$} & \\
\hline
\end{tabular}

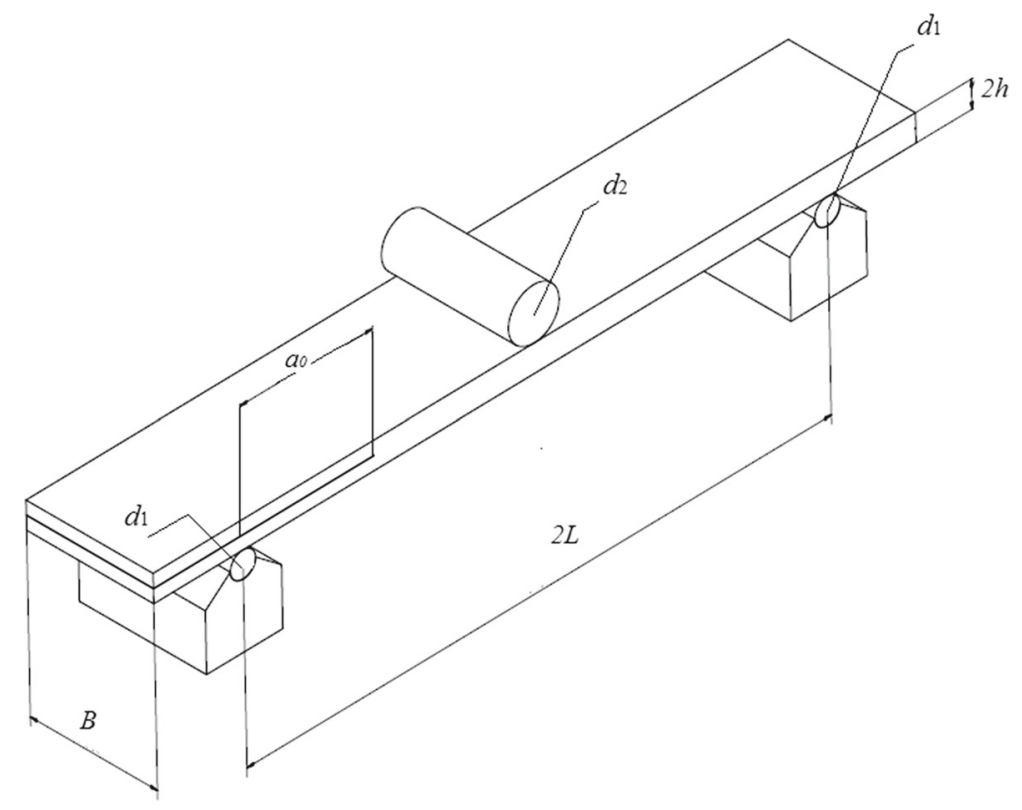

Fig. 1 ENF test setup

the literature, it was also decided to test the multidirectional laminates with different delamination interfaces in which specimen stacking sequences avoid excessive elastic couplings because of low values of the nondimensional parameters. All types of ENF specimens with different stacking sequences and interfaces were designed and fabricated according to ASTM D7905 Standard and were listed in Table 3. The laminate material was ThinPreg 736 LT carbon/epoxy composite prepreg. The average thickness of each lamina in the specimens was $0.131 \mathrm{~mm}$. Material properties were summarized in Table 1 . The geometric dimensions of the specimens were illustrated in Fig. 1, where $2 h=4.98 \mathrm{~mm}$ denotes the total thickness of the ENF specimen, $B=25 \mathrm{~mm}-$ width of the specimen, $2 L=175 \mathrm{~mm}$ - distance between support rollers and $a_{0}=30 \mathrm{~mm}$ indicates the initial crack length. A 0.013 -mm-thick PTFE foil was inserted into the mid-plane of the laminates at one edge to separate the whole laminate into two sub-laminates (two arms) and acted as an artificial delamination or starter crack.

\subsection{Test procedure}

The end-notched flexure tests were carried out with the Shimadzu ASG-X universal tensile testing machine equipped with $1 \mathrm{kN}$ load cell and the three-point bending fixture (MTS 642.10B-3PB apparatus). All exper- 
iments were prepared according to the ASTM D7905 Standard. During the tests specimens were placed on two support rollers with diameter $d_{1}=5 \mathrm{~mm}$ as it was shown in Fig. 1. Loading was realized by central roller with diameter $d_{2}=10 \mathrm{~mm}$. Twice a big diameter of loading roller was used in order to evade local damage by indentation. Machine crosshead worked in compression direction with constant speed equal $1 \mathrm{~mm} / \mathrm{min}$ in order to induce the mode II fracture circumstances. Prior to any tests, a light coating of white paint was applied to the specimen's edges in order to facilitate the visual detection of delamination front. During the ENF experiment the applied load $P$ and the load displacement point $\delta$ were registered. Also delamination onset as well as all propagation values were visually observed and marked on the specimens edges.

\subsection{Identification of delamination onset}

In the present study the interlaminar toughness was studied at crack initiation. Therefore, properly determination of the initiation point played a vital role in determination of the $G_{\text {IIC }}$. In the experiments led by the author of the current paper the difficulties with precise determination of delamination onset point were experienced. Knowledge of the actual value of the load corresponding to delamination onset is, however, of particular importance while computing the mode II fracture toughness in accordance with the respective standardized methods. Any uncertainty in experimental identification of the fracture onset load can lead to generating the inaccurate results in the $G_{\text {IIC }}$ calculations. However, the identification of the crack initiation point remains ambiguous, since the formation of the large FPZ often causes considerable nonlinearity before the peak load. The corresponding point called $(N L)$ is not always easy to identify and remains subjective because of it may arise from geometrical effects. Therefore, the ASTM D7905 Standard for the ENF test only retains the maximum load point $\left(P_{\max }\right)$ as a crack initiation criterion. However, the $N L$ point is a well-known standard initiation in fracture tests and thus is likely to remain in use. Furthermore, it can be argued that the damage energy accumulated between the $N L$ and $P_{\max }$ points may be relevant for some design applications, e.g., by promoting interply cracking and fatigue failure modes. Therefore, it is prudent to have a definition more closely related to physical events and for that purpose the acoustic emission recordings were made. The point called $A E$ corresponded to the first rapid increase of cumulative counts of the acoustic emission signal recorded during the test and was taken into account as definition of delamination onset.

\subsection{Acoustic emission technique}

Owing to experienced difficulties in defining the exact crack initiation moment and the respective point at the experimentally obtained load-displacement curves the acoustic emission equipment was used as an additional data source. The piezoelectric AE (Fujicera 1045S, max. 1.3 MHz) sensor was embedded on top surface of the specimen in $20 \mathrm{~mm}$ ahead of the specimen end edges. The load signal indicated by Shimadzu ASG-X was split and sent to AE system in real time. Elastic waves of AE signal were registered continuously at a $10-\mathrm{MHz}$ sampling rate by using AMSY-5 acoustic emission acquisition system consisting of pre-amplifier (AEP-4, $34 \mathrm{~dB}$ of gain) and analog-to-digital (A/D) card (Vallen'sASIP-2, sampling frequency $40 \mathrm{MHz}$ resolution-18 bits, band width 1.6-2400 kHz). During the tests the number of events and the energy of the elastic waves were registered.

Figures 2 and 3 present load and number of events (in the form of cumulative counts) versus time obtained during the fracture toughness ENF tests prepared on composite coupled laminates. Researches revealed usefulness of the acoustic emission method in determination of delamination onset and - consequently-high accuracy of the initial c-SERR determination. For both laminates delamination initiated explicitly before the maximum point $\left(P_{\max }\right)$ on the load versus time curve.

\subsection{Data reduction method}

\subsubsection{Classical methods}

In order to obtain the mode II critical strain energy release rate (c-SERR) two different data reduction schemes described in the ASTM D7905 standard were used, namely: the direct beam theory (DBT) and the corrected 


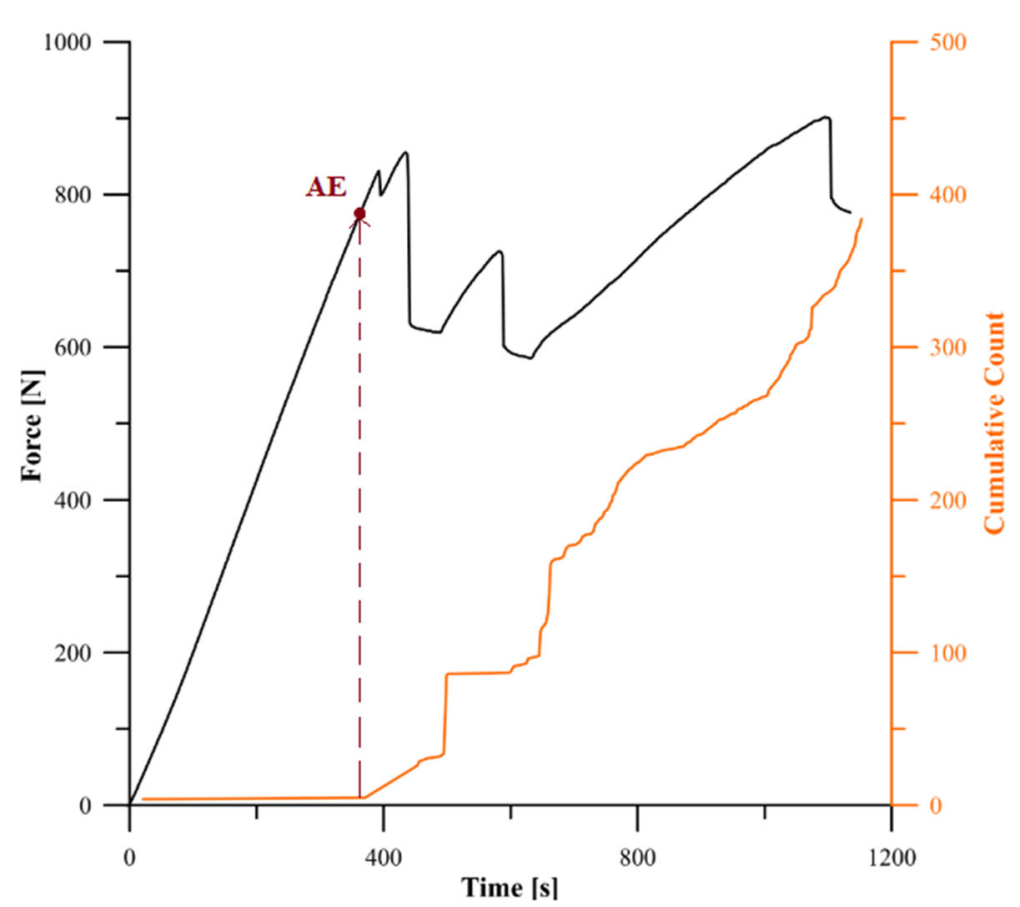

Fig. 2 Load and cumulative count versus time for the laminate exhibiting the bending-extension coupling

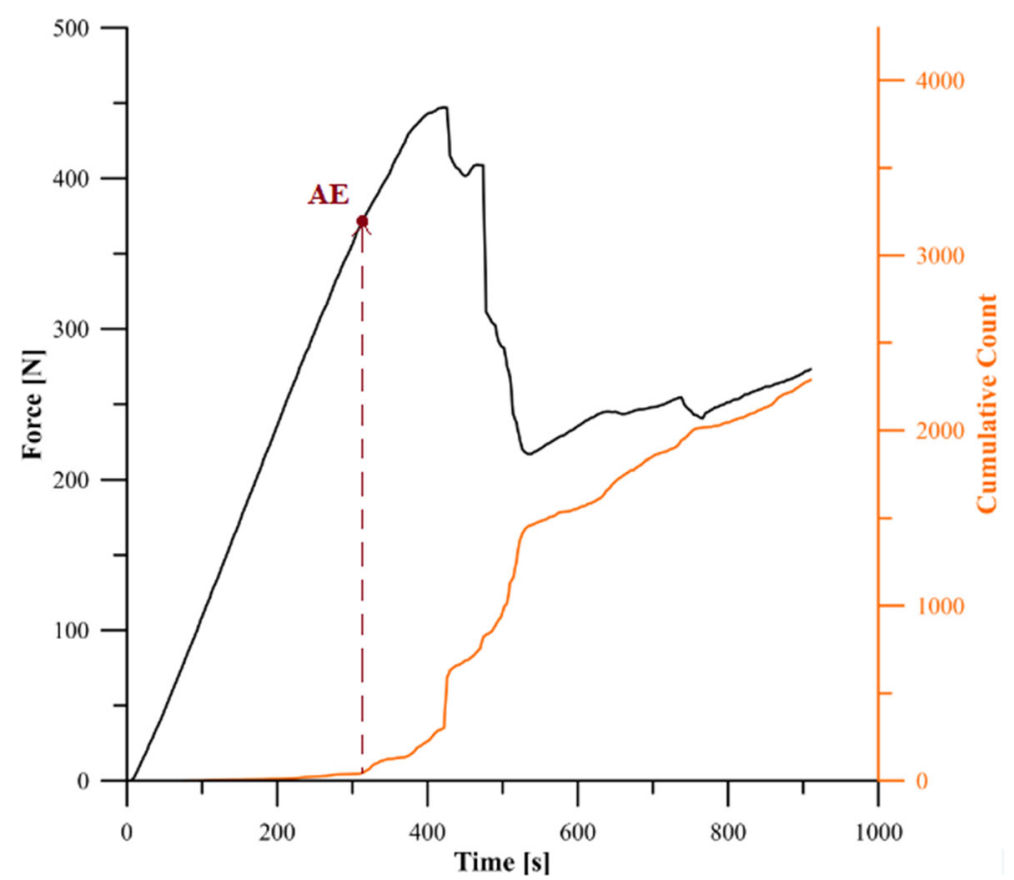

Fig. 3 Load and cumulative count versus time for the laminate exhibiting the bending-twisting coupling

beam theory (CBT). For the first method, $G_{\text {IIC }}$ was determined from the following formula:

$$
G_{\text {IIC }}=\frac{9 a^{2} P \delta}{2 B\left(2 L^{3}+3 a^{3}\right)}
$$


For the CBT method, the $G_{\text {IIC }}$ was determined as follows:

$$
G_{\text {IIC }}=\frac{9 a^{2} P^{2}}{16 B^{2} h^{3} E_{f}}
$$

Here, $E_{f}$ is the axial modulus which was calculated according to Eq. (11) and $C_{0}$ is the initial compliance at $a=a_{0}$, as determined from the experimental compliance procedure.

$$
E_{f}=\frac{L^{3}}{4 B h^{3} C_{0}}
$$

\subsubsection{Compliance based beam method (CBBM)}

The previous methods (DBT, CBT) depend on accurate crack length measurements during propagation which is not easy to perform. In fact, a fracture process zone develops ahead of crack tip in consequence of multiple microcracks and plastification. This phenomenon renders difficult the identification of the crack tip localization. The method proposed by de Moura [27] described in this section takes into account these features and is named the compliance-based beam method (CBBM). This method is based on Timoshenko beam theory which predicts the ENF specimen compliance as

$$
C=\frac{3 a^{3}+2 L^{3}}{8 B h^{3} E_{1}}+\frac{3 L}{10 B h G_{13}}
$$

where $E_{1}, G_{13}$ designate the longitudinal and shear elastic moduli, respectively. Remaining geometric parameters were identified in Fig. 1. The initial compliance $C_{0}$ and crack length $a_{0}$ can be used to determine a corrected flexural modulus.

$$
E_{f}=\frac{3 a_{0}^{3}+2 L^{3}}{8 B h^{3}}\left(C_{0}-\frac{3 L}{10 B h G_{13}}\right)^{-1} .
$$

In order to account for several features that are not included in beam theory (e.g., stress concentration at the crack tip or root rotation effects) the experimental compliance $C$ is used to determine an effective crack length $a_{\mathrm{e}}$ by means of Eqs. (12) and (13),

$$
a_{e}=\left[\frac{C_{c}}{C_{0 C}} a_{0}^{3}+\frac{2}{3}\left(\frac{C_{c}}{C_{0 C}}-1\right) L^{3}\right]^{\frac{1}{3}}
$$

where

$$
C_{C}=C-\frac{3 L}{10 B h G_{13}} ; \quad C_{0 C}=C_{0}-\frac{3 L}{10 B h G_{13}} .
$$

Therefore, combining equations (12) with the Irwin-Kies equation,

$$
G_{\text {IIC }}=\frac{P^{2}}{2 B} \frac{d C}{d a}
$$

yields

$$
G_{\mathrm{IIC}}=\frac{9 P^{2} a_{e}^{2}}{16 B^{2} h^{3} E_{f}}
$$




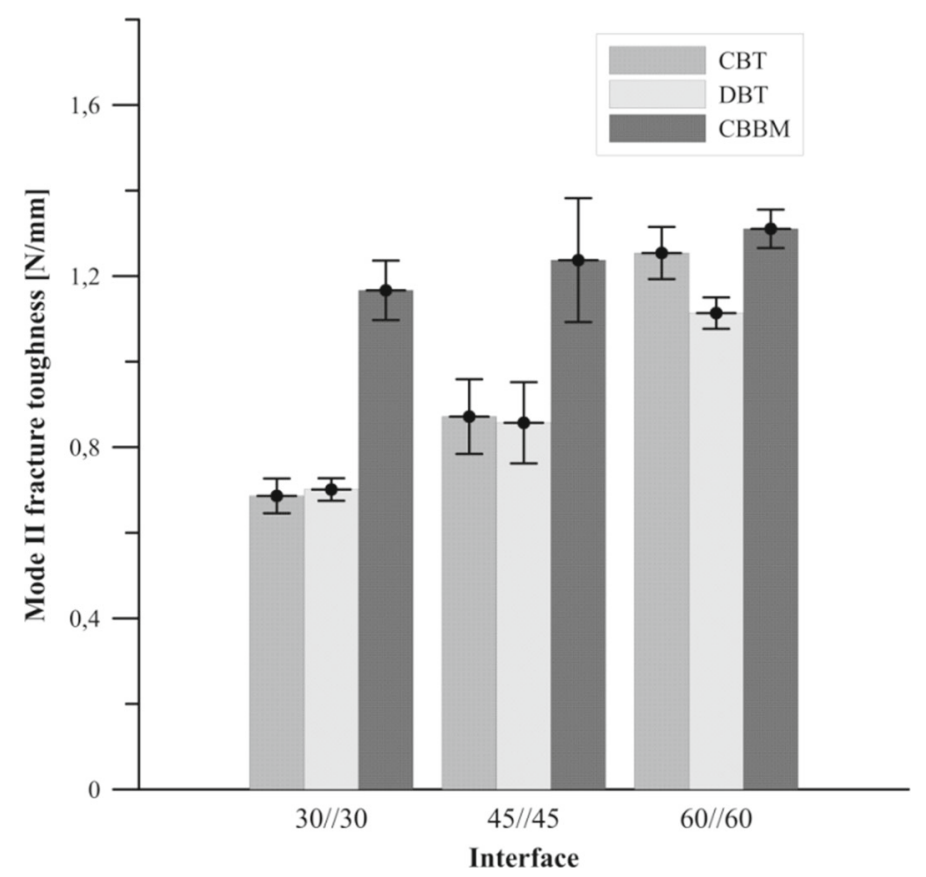

Fig. 4 Mode II fracture toughness obtained for laminates with $\theta / / \theta$ delamination interface by using different calculation methods

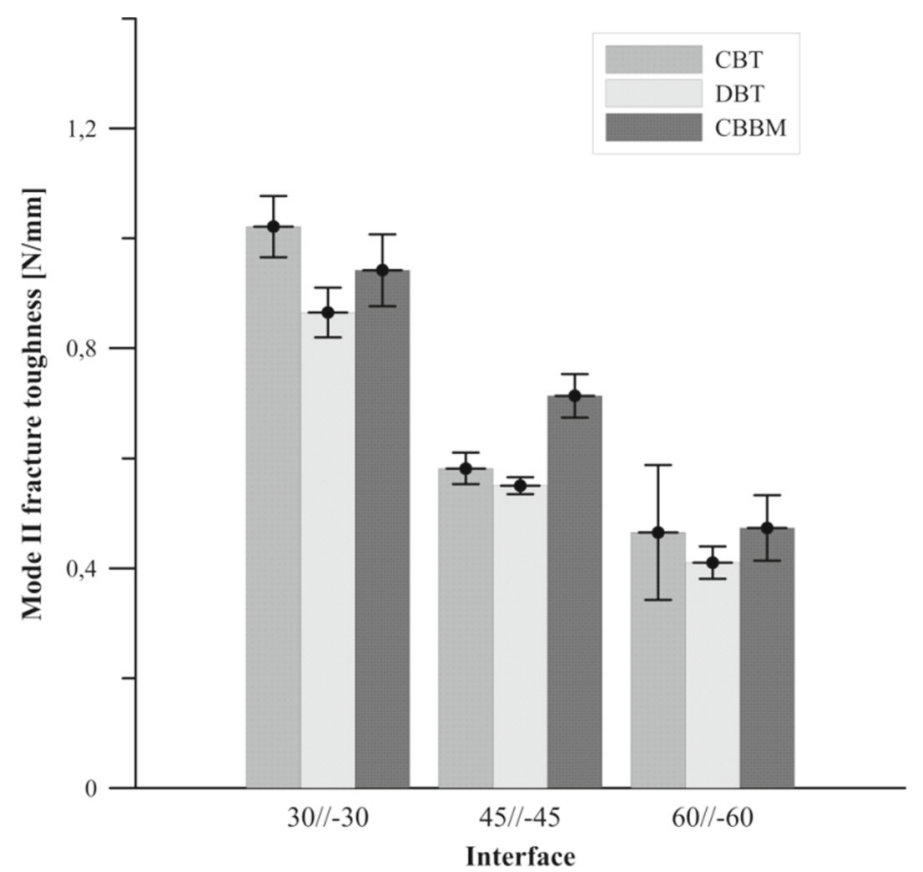

Fig. 5 Mode II fracture toughness obtained for laminates with $\theta / /-\theta$ delamination interface by using different calculation methods

\section{Results and discussion}

Figures 4 and 5 present results of calculations of the mode II fracture toughness of multidirectional laminates with different ply orientation angles at delamination plane. For specimens with $\theta / / \theta$ interface the critical strain energy release rate increased with growth of $\theta$ angle. Namely, the c-SERR values obtained by using the corrected beam theory were respectively $0.686 \mathrm{~N} / \mathrm{mm}$ for specimen with $30^{\circ} / / 30^{\circ}$ interface, $0.872 \mathrm{~N} / \mathrm{mm}$ for $45^{\circ} / / 45^{\circ}$ 


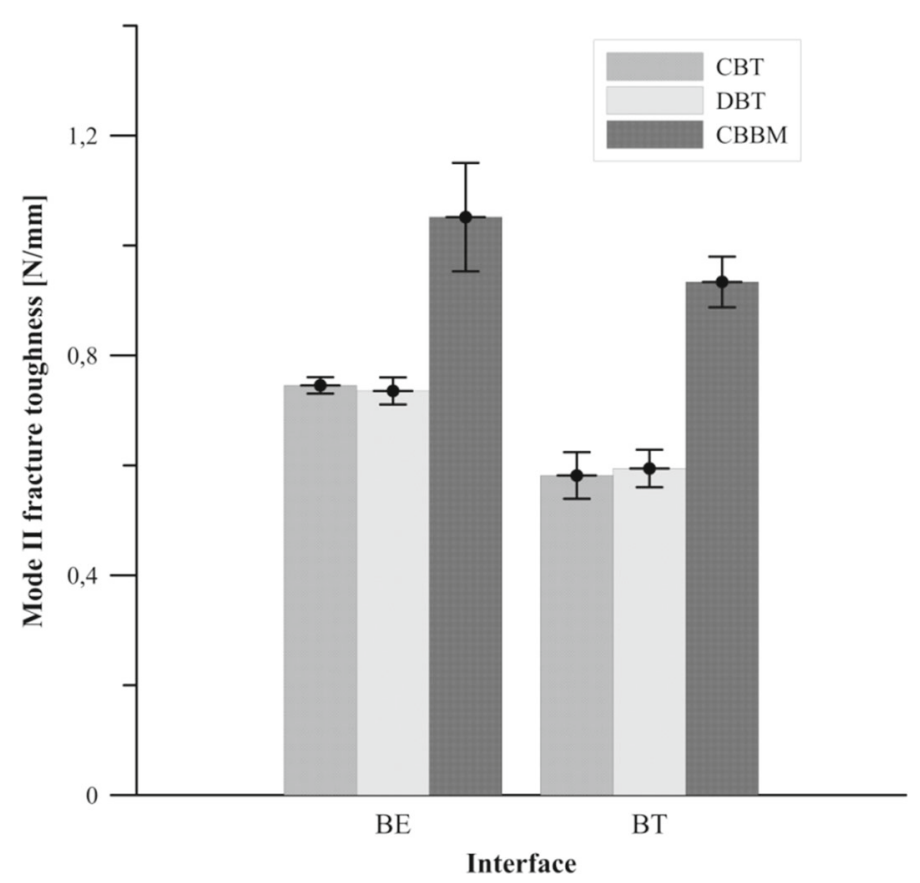

Fig. 6 Mode II fracture toughness obtained for laminates with the bending-twisting and the bending-extension couplings by using different calculation methods

interface and $1.254 \mathrm{~N} / \mathrm{mm}$ for $60^{\circ} / / 60^{\circ}$ interface. Results obtained by using the direct beam theory and the corrected beam theory were on similar level. The greatest discrepancies between values of the $G_{\text {IIC }}$ calculated by using those methods were obtained for the $60^{\circ} / / 60^{\circ}$ specimen. Opposite situation was observed for the $\theta / /-\theta$ composite laminates. For those laminates, the critical strain energy release rate decreased with growth of $\theta$ angle reaching maximum value equal $1.021 \mathrm{~N} / \mathrm{mm}$ for specimen with $30^{\circ} / /-30^{\circ}$ delamination interface and minimum value $G_{\mathrm{IIC}}=0.465 \mathrm{~N} / \mathrm{mm}$ for $60^{\circ} / /-60^{\circ}$ specimen. Laminate with interface $45^{\circ} / /-45^{\circ}$ exhibited value of the c-SERR equal $0.582 \mathrm{~N} / \mathrm{mm}$. Moreover, in the case of specimen with $\theta / /-\theta$ interfaces results obtained by using different standardized methods were also on similar level. Nevertheless, fracture toughness calculated by using the compliance-based beam method for all multidirectional specimens gave greater values than results obtained by using the classical data reduction schemes. Globally, those differences could be explained by the effect of the fracture process zone. In fact, the CBT method does not account for this damaged region which influences the compliance. Direct beam theory is expected to give more precise results in this point of view because it includes $P$ and $\delta$ in its equation instead of load alone. On the other hand, the compliance-based beam method captures the effect of FPZ and thus yields much more accurate toughness values.

Values of the critical strain energy release rate obtained for specimens with the bending-twisting and the bending-extension couplings were presented in Fig. 6. Comparing the results obtained by using the standardized data reduction methods the greatest values of the c-SERR were obtained for the BE specimen and were equal $0.746 \mathrm{~N} / \mathrm{mm}$ (for the CBT method) and 0.735 (for the DBT method). For the BT laminate the fracture toughness values were equal $0.582 \mathrm{~N} / \mathrm{mm}$ and $0.594 \mathrm{~N} / \mathrm{mm}$ for the corrected beam theory and the direct beam theory, respectively. In this case, results obtained by using the compliance-based beam method were much more greater and reached maximum equal $1.052 \mathrm{~N} / \mathrm{mm}$ for the bending-extension laminate and minimum equal $0.934 \mathrm{~N} / \mathrm{mm}$ for the bending-twisting laminate. Considerable discrepancies between results obtained from the classical methods and the method based on equivalent crack concept might be caused by larger fracture process zone which resulted from the mode II circumstances and presence of elastic couplings. Moreover, non-zero components in the matrices the $\mathbf{B}$ and $\mathbf{D}$ might influenced arising shearing deformation and twisting curvatures at delamination front which might caused errors in the mode II fracture toughness measurements, even if accurate observations of the crack positions were achieved. Influence of elastic couplings on behavior of the bending-extension laminate subjected to the ENF test was presented in Fig. 7 where transverse shearing of sub-laminates was observed. Although this phenomena was observable only for large deflection it could influence on the fracture toughness at delamination initiation. 


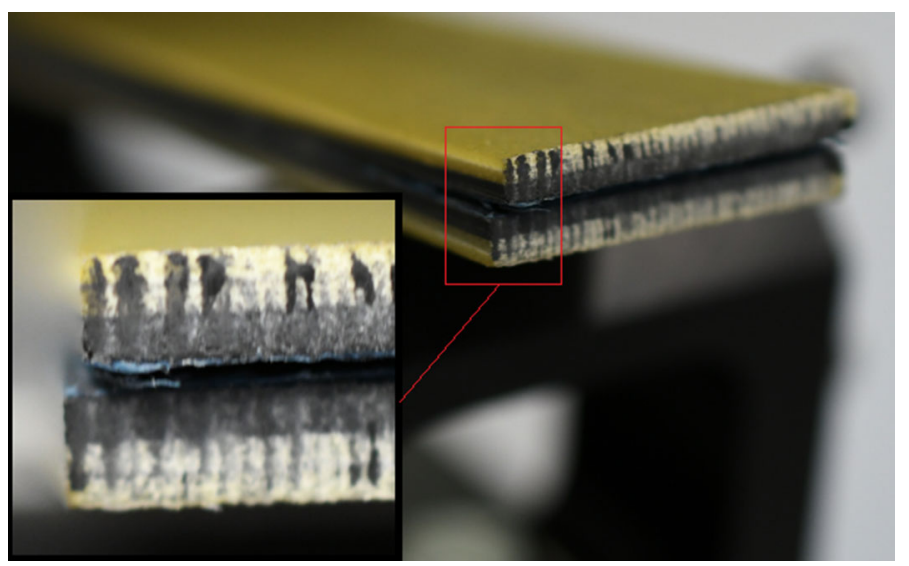

Fig. 7 Transverse shearing effect observed for the bending-extension laminate subjected to the ENF test
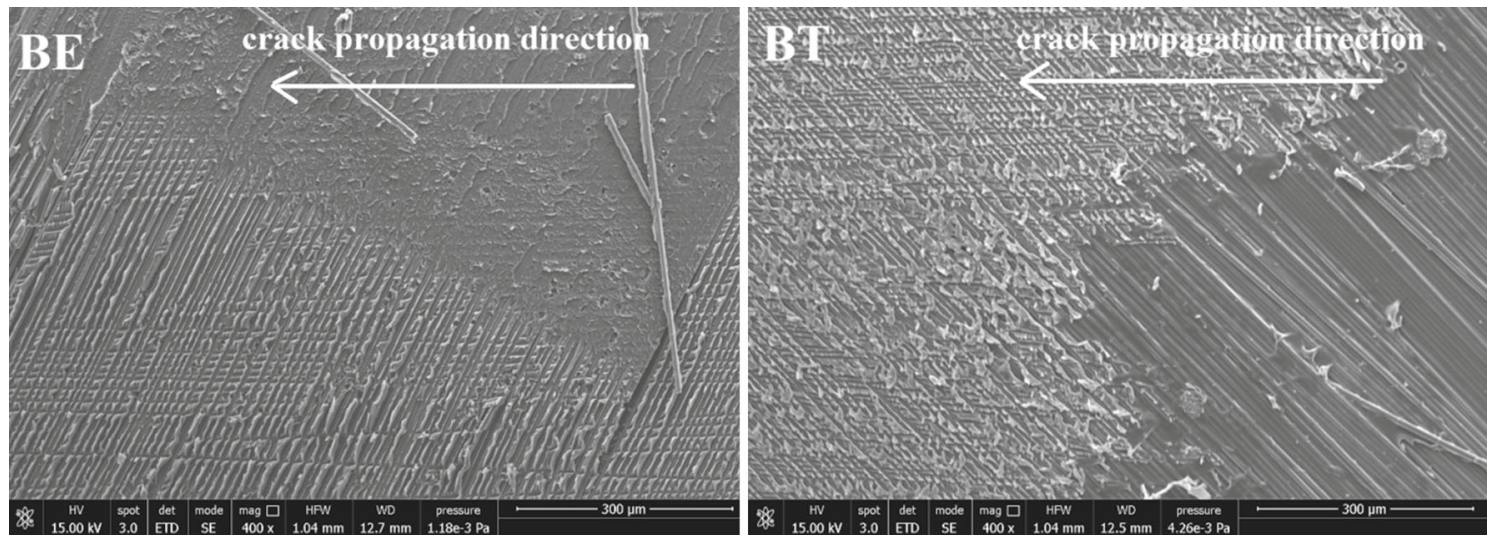

Fig. 8 Delamination surfaces of the bending-extension and the bending-twisting specimens after the ENF tests

Figure 8 shows the comparison of scanning electron microscope (SEM) photographs of fracture surfaces after the ENF tests for the bending-extension and the bending-twisting laminates. The investigation showed the mode II-dominated shear fracture for all tested laminates. In addition, for both specimens delamination surfaces exhibited a very rough fracture plane with the characteristic hackles attributed to the mode II delamination which were created by coalescence of numerous, small, tensile microcracks that formed between the fibers under the shear loading. The hackles were quite varied over the fracture surfaces on the BE and BT specimens which could be caused by the actual percentage of the local mode I versus mode II or mode III load conditions, the amount of resin between the fibers and the orientation of those fibers. Smooth fracture surface observed on the $\mathrm{BE}$ laminate delamination plane was dominated by matrix failure. For the specimen with the bending-twisting coupling some evidence of the mode I tension fracture could be seen. It might be caused by $D_{16}$ component of the bending stiffness matrix which produced twisting curvature around central axis and-in consequence tensile load contribution. On the other hand, non-zero components in the coupling stiffness matrix for the bending-extension laminate caused shearing deformation which was shown in Fig. 7. Moreover, the hackles observed on delamination plane of the BE specimen were perpendicular to the fibers and not to the crack propagation direction. This would suggest a presence of the local mode III fracture component. The strain energy release rates obtained during the experiments were slightly greater for the bending-extension specimen than for the bending-twisting laminate. It could be explained by contribution of the mode III that correlated with greater fracture toughness energy and showed material's ability to absorb more energy under the mode II loading. Although some fibers breakage were observed, its contribution to the total fracture work was deemed minor. Moreover, for all coupled specimens an interlaminar delamination was observed which was desirable in the experimental point of view. 


\section{Conclusions}

Experimental ENF tests were prepared according to the ASTM D7905 Standard on multidirectional laminates with different delamination interfaces and laminates exhibiting the bending-extension and the bendingtwisting elastic couplings. Critical strain energy release rates were calculated by using standardized data reduction methods and the compliance-based beam method. Results showed that the fracture toughness values obtained for the classical data reduction schemes were lower than for the CBBM method. It might be explained by effect of the fracture process zone. In fact, even if accurate observations of the crack position were achieved the corrected beam theory and the direct beam theory fail to take into account the FPZ. Moreover, elastic coupling phenomena can introduce errors in the mode II strain energy release rate determination. The nonzero terms in the coupling stiffness matrix caused transverse shearing of the BE laminate. In addition, elastic coupling phenomena influenced on curved delamination front which was subsequent source of errors during experimental determination of the critical strain energy release rate. Fractographic analysis prepared after the ENF tests on coupled laminates confirmed contribution of the opening mode I and the transverse mode III components during delamination process.

The acoustic emission method turned out to be a very helpful technique in recognizing delamination initiation. The AE point corresponding to the first sharp growth of cumulative count was taken into account as delamination onset. Moreover, the AE investigations revealed that delamination initiated before the maximum point on the load-displacement plot without any observable crack propagation. Thus, effect of the fracture process zone was confirmed.

To sum up, applicability of the end-notched flexure test to carbon/epoxy composite laminates exhibiting elastic couplings can be prepared in the case of measurements of the total fracture toughness. The acoustic emission technique and additional data reduction method allowed to precise determination of the total delamination resistance of laminates subjected to the bending load. On the other hand, percentage contribution of the opening mode I and transverse shear mode III in the ENF test should be recognized by using an additional method, i.e., numerical analysis, when pure mode II is determined.

Acknowledgements The paper was financially supported by the Ministerial Research Project No. DEC-2016/21/B/ST8/03160 financed by the Polish National Science Centre.

Open Access This article is licensed under a Creative Commons Attribution 4.0 International License, which permits use, sharing, adaptation, distribution and reproduction in any medium or format, as long as you give appropriate credit to the original author(s) and the source, provide a link to the Creative Commons licence, and indicate if changes were made. The images or other third party material in this article are included in the article's Creative Commons licence, unless indicated otherwise in a credit line to the material. If material is not included in the article's Creative Commons licence and your intended use is not permitted by statutory regulation or exceeds the permitted use, you will need to obtain permission directly from the copyright holder. To view a copy of this licence, visit http://creativecommons.org/licenses/by/4.0/.

\section{References}

1. American Society for Testing and Materials. ASTM D7905M-14, Standard Test Method for Determination of the Mode II Interlaminar Fracture Toughness of Unidirectional Fiber-Reinforced Polymer. Accessed 2014

2. International Standard Organization. ISO 15114:2014, Fibre-reinforced Plastic Composites-Determination of the Mode II Fracture Resistance for Unidirectionally Reinforced Materials using the Calibrated End-loaded Split (C-ELS) Test and an Effective Crack Length Approach. Accessed 2014

3. American Society for Testing and Materials. ASTM D6671/D6671M, Standard Test Method for Mixed Mode I-Mode II Interlaminar Fracture Toughness of Unidirectional Fiber Reinforced Polymer Matrix Composites. Accessed 2013

4. Pérez-Galmés, M., Renart, J., Sarrado, C., Brunner, A.J., Rodríguez-Bellido, A.: Towards a consensus on mode II adhesive fracture testing: experimental study. Theor. Appl. Fract. Mech. 98, 210-219 (2018)

5. Liu, W., Chen, P.: A simple procedure for the determination of the cohesive law in 4-ENF test with consideration of the friction and R-curve effect. Eng. Fract. Mech. 220, 106651 (2019)

6. Bonhomme, J., Mollón, V., Viña, J., Argüelles, A.: Modelling ENF test procedure by means of the two-step extension method. Influence of friction forces. Polym. Test. 30, 856-860 (2011)

7. Srivastava, V.K., Gries, T., Veit, D., Quadflieg, T., Mohr, B., Kolloch, M.: Effect of nanomaterial on mode I and mode II interlaminar fracture toughness of woven carbon fabric reinforced polymer composites. Eng. Fract. Mech. 180, 73-86 (2017)

8. Srivastava, V.K., Gries, T., Quadflieg, T., Mohr, B., Kolloch, M., Kumar, P.: Fracture behavior of adhesively bonded carbon fabric composite plates with nano materials filled polymer matrix under DCB, ENF and SLS tests. Eng. Fract. Mech. 202, 275-287 (2018)

9. Reis, J.P., de Moura, M.F.S.F., Moreira, R.D.F., Silva, F.G.A.: Pure mode I and II interlaminar fracture characterization of carbon-fibre reinforced polyamide composite. Compos. B Eng. 169, 126-132 (2019) 
10. Raghu Prasad, B.K., Pavan Kumar, D.V.T.G.: Analysis of composite ENF specimen using higher order beam theories. Thin Walled Struct. 46, 676-688 (2008)

11. de Morais, A.B.: Analysis of mode II interlaminar fracture of multidirectional laminates. Compos. A Appl. Sci. Manuf. 35, 51-57 (2004)

12. Mollón, V., Bonhomme, J., Argüelles, A., Viña, J.: Influence of the crack plane asymmetry over GII results in carbon epoxy ENF specimens. Compos. Struct. 94, 1187-1191 (2012)

13. Jumel, J., Budzik, M.K., Ben Salem, N., Shanahan, M.E.R.: Instrumented end notched flexure—crack propagation and process zone monitoring. Part I: modelling and analysis. Int. J. Solids Struct. 50, 297-309 (2013)

14. Hosseini, M.R., Taheri-Behrooz, F., Salamat-talab, M.: Mode II interlaminar fracture toughness of woven E-glass/epoxy composites in the presence of mat interleaves. Int. J. Adhes. Adhes. 98, 102523 (2020)

15. Fernández, M.V., de Moura, M.F.S.F., da Silva, L.F.M., Marques, A.T.: Characterization of composite bonded joints under pure mode II fatigue loading. Compos. Struct. 95, 222-226 (2013)

16. Boyano, A., de Gracia, J., Arrese, A., Mujika, F.: Experimental assessment of an End Notched Flexure test configuration with an inserted roller for analyzing mixed-mode I/II fracture toughness. Eng. Fract. Mech. 163, 462-475 (2016)

17. Rzeczkowski, J., Samborski, S., Valvo, P.S.: Effect of stiffness matrices terms on delamination front shape in laminates with elastic couplings. Compos. Struct. 233, 111547 (2020)

18. Samborski, S.: Numerical analysis of the DCB test configuration applicability to mechanically coupled Fiber Reinforced Laminated Composite beams. Compos. Struct. 152, 477-487 (2016). https://doi.org/10.1016/j.compstruct.2016.05.060

19. Davidson, B.D., Kruger, R., Konig, M.: Effect of stacking sequence on energy release rate distribution in multidirectional DCB and ENF specimens. Eng. Fract. Mech. 55, 557-569 (1996)

20. Samborski, S.: Analysis of the end-notched flexure test configuration applicability for mechanically coupled fiber reinforced composite laminates. Compos. Struct. 163, 342-349 (2017)

21. Ozdil, F., Carlsson, L.A., Davies, P.: Beam analysis of angle-ply laminate end-notched flexure specimens. Compos. Sci. Technol. 58, 1929-1938 (1998)

22. Pereira, A.B., de Morais, A.B., Marques, A.T., de Castro, P.T.: Mode II interlaminar fracture of carbon/epoxy multidirectional laminates. Compos. Sci. Technol. 64, 1653-1659 (2004)

23. Pereira, A.B., de Morais, A.B.: Mode II interlaminar fracture of glass/epoxy multidirectional laminates. Compos. A Appl. Sci. Manuf. 35, 265-272 (2004)

24. Pereira, F.A.M., de Moura, M.F.S.F., Dourado, N., Morais, J.J.L., Xavier, J., Dias, M.I.R.: Determination of mode II cohesive law of bovine cortical bone using direct and inverse methods. Int. J. Mech. Sci. 138-139, 448-456 (2018)

25. Dourado, N., de Moura, M.F.S.F., de Morais, A.B., Pereira, A.B.: Bilinear approximations to the mode II delamination cohesive law using an inverse method. Mech. Mater. 49, 42-50 (2012)

26. Davidson, B.D., Kruger, R., Konig, M.: Three dimensional analysis and resulting design recommendations for unidirectional and multi-directional end-notched flexure tests. J. Compos. Mater. 29, 2108 (1995)

27. de Moura, M.F.S.F., de Morais, A.B.: Equivalent crack based analyses of ENF and ELS tests. Eng. Fract. Mech. 75, 2584-2596 (2008)

Publisher's Note Springer Nature remains neutral with regard to jurisdictional claims in published maps and institutional affiliations. 